\title{
Knowledge, attitude and practices of breast feeding in primigravida women in tertiary care hospital in central India
}

\author{
Waikar $\mathbf{A}^{1}$, Bhalerao $\mathbf{A}^{2}$, Waikar $\mathbf{M}^{3}$ \\ ${ }^{1}$ Dr Ashwini Waikar, Intern at NKPSIMS, Nagpur, Maharashtra, ${ }^{2}$ Dr. Anuja Bhalerao, Associate Professor, \\ Department of Obs-Gyn, NKPSIMS, Nagpur Maharashtra, ${ }^{3}$ Dr. Manjushri Waikar, Professor, Dept of Obs-Gyn, \\ GMC, Chandrapur Maharashtra, India.
}

Address for Correspondence: Dr. Manjushri Waikar, Professor Dept of Obs-Gyn, GMC, Chandrapur Maharashtra, India, Email: manjuw123@gmail.com

\begin{abstract}
Introduction: There are gaps between UNICEF and BFHI recommendations and actual implementations of breastfeeding practices due to inadequate counseling of primigravida on breastfeeding, reflected nationally as poor infant nutritional status. Objectives: The study aims to assess the knowledge, attitude and practices of primigravida about breastfeeding, counsel the primigravida women on the prescribed scientific breastfeeding methods, to analyze the change in their perspective about breastfeeding after counseling and to suggest recommendations based on findings. Methods: Questionnaire based descriptive cross sectional study conducted on selected 75 primigravida with gestational age of 36 weeks or more, attending ANC OPD or admitted to NKPSIMS during April and May 2014 after consent. A structured validated pre/posttest questionnaire was administered to assess the knowledge, attitude and practices of breastfeeding of participants. Demographic variables were recorded. Pretest was conducted, followed by counseling on the importance of breastfeeding, maternal nutrition, duration of exclusive breastfeeding, mother's and baby's position during breastfeeding using flashcards which was followed by posttest on the same questionnaire. The data was analyzed using SPSS software Open Epi Info version 2.3 year 2009. P values $<0.05$ were considered as statistically significant. Results: Comparison of pre/posttest results showed statistically significant change in importance of exclusive breast feeding, colostrum, early initiation, suitable position and duration of breastfeeding, perception of baby's satisfaction and stool color, maternal nutrition and breast problems during lactation after counseling. Conclusion: Antenatal breastfeeding counseling must be strengthened by a multi pronged individualized approach, reinforcement focusing on the recommended practices of breastfeeding to promote and sustain breastfeeding.
\end{abstract}

Key words: Breast feeding, Knowledge attitude and practices, Primigraviada, Counseling

\section{Introduction}

The nutritional well being of a population is outcome and indicator of national development [1]. Breastfeeding has a major role in determining the nutritional status of the infant. A strong link between malnutrition and breastfeeding has been well established.

There are many programs which are run by the ministry of health, UNICEF (United Nations International Children's Emergency Fund) and

Manuscript received: $18^{\text {th }}$ June 2017

Reviewed: $28^{\text {th }}$ June 2017

Author Corrected: $7^{\text {th }}$ July 2017

Accepted for Publication: $15^{\text {th }}$ July 2017
BFHI (Baby Friendly Hospital Initiative) for encouraging and promoting exclusive breastfeeding of infants till the age of 6 months [2]. These educative programs however do not address to the needs of individual mothers and there are gaps between the recommendations and implementation.

In rural India most of the women get pregnant soon after marriage. Adolescents have unique needs in the pregnancy \& postpartum [3]. They are physically, emotionally and mentally incompetent to handle the changing demands of the family and society. These women are likely to be influenced 
by the experienced women family members, their friends who have breastfed their babies, the treating doctors and of course the media [4] leading to confusion in the minds of these primigravida women. At such times they often fall back upon the traditional knowledge given by the elders in the family which has been passed down generations, which is often contradictory to what has been scientifically proven [5].

The prevalence of malnutrition among children in rural areas throws light upon the fact that primigravida mothers are still incompetent and need to be counseled on a one to one basis and their knowledge attitude and practices about breastfeeding need to be addressed[6]. It was found that primigravida status adversely affects breastfeeding, therefore counseling and support should be focused on this group. This study is being carried out in view of this important fact and lack of large studies, especially in rural areas.

\section{Aims and Objectives}

1)To assess the knowledge, attitude and practices of primigravida about breastfeeding.

2)To counsel the primigravida women on the prescribed scientific methods of breastfeeding.

3) To analyze the change in their perspective about breastfeeding after counseling.

4)To suggest recommendations based on study findings.

\section{Material and Methods}

Study Design -Questionnaire based descriptive cross sectional study

Setting- Tertiary care rural hospital at NKP Institute Salve of Medical sciences, Digdoh hills, Hingna, Nagpur.

\section{Inclusion criteria}

1. Random sampling of the primigravida mothers who were 36 weeks pregnant and above attending the ANC OPD or admitted to the tertiary care rural hospital.

2. Primigravida mothers who were willing to participate in the study.

3. Primigravida mothers who could read and write in Hindi and Marathi.

\section{Exclusion criteria}

1. Primigravida mothers who were not willing to participate in the study.

2. Primigravida mothers who were unable to read and write in Hindi and Marathi.

3. Primigravida mothers who were admitted as emergency.

4. Primigravida who were pregnant below 36 weeks, as they did not deliver during the data collection period.

5. Multigravida women.

Participants- 75 primigravida mothers satisfying the inclusion criteria of gestational age of 36 weeks or more attending Antenatal Care (ANC) OPD or admitted to the ward or labour room in tertiary care rural hospital were studied

Variables- The studied demographic variables included gestational age, maternal age, religion, type of family (nuclear or joint), maternal education and maternal occupation. Questions pertaining to the importance of breast feeding, diet during breast feeding, duration of exclusive breastfeeding, mother's and baby's position during breastfeeding, indicators of baby's satisfaction and common breast problems during breast feeding..

The data collection procedure was carried out for a period of 2 months during April and May 2014. The study was carried out after obtaining permission from the ethics committee of the tertiary care rural hospital.

Data Source: A structured validated pre/posttest questionnaire to access the knowledge, attitude and practices related to breastfeeding was designed. The questions were direct, easy to answer, in which options of the possible answers were provided. Questions included information on demographic variables of the mothers and questions to assess the knowledge, attitude and practices about breastfeeding.

Bias - Bias due to random sampling

Study Size- 75 Primigravida mothers

Statistical methods: The data collected was analyzed using SPSS software. Percentages, mean, standard deviation and Chi square test were calculated using statistical software OpenEpi Info 
version 2.3 year 2009.P values less than 0.05 were considered as statistically significant. The Chi Square Test, trend and analysis of variance (ANOVA) was used for statistical analysis.

\section{Methodology}

- The data was collected from randomly selected primigravida mothers admitted or attending ANC OPD after obtaining their consent and collecting the demographic variables.

- The primigravida women were administerd the pretest questionnaire to collect baseline information.
- These primigravida mothers were then counseled by the investigator using flashcards on the prescribed scientific methods, importance of colostrum, diet, duration of exclusive breastfeeding, mother's and baby's position, problems during breastfeeding etc. as relevant and pertinent to the questionnaire.

- Then the primigravida mothers were administered the same questionnaire to assess change in knowledge, attitude and practices about breastfeeding after delivery. The interval between pre /posttest questionnaire ranged from 4 days to 1 month.

\section{Results}

Before counseling $53.33 \%$ did not know the importance of colostrum. After counseling $100 \%$ the subjects came to know that colostrum is essential and should be given to the baby. There was a change in the perception about the healthy baby from $88 \%$ to $100 \%$.

After counseling, all the subjects $(100 \%)$ came to know that the diet has to be a balanced combination of protein, Iron, Calcium and calories

Table-1: Showing opinion about the best position for the mother while feeding.

\begin{tabular}{|c|c|c|c|c|}
\hline \multirow{2}{*}{ Options } & \multicolumn{2}{|c|}{ Pretest } & \multicolumn{2}{c|}{ Post test } \\
\cline { 2 - 5 } & No & Percent & No & Percent \\
\hline Side lying & 5 & 6.66 & 0 & 0 \\
\hline Sitting position & 45 & 60 & 0 & 0 \\
\hline Standing position & 0 & 0 & 0 & 0 \\
\hline Prone position & 2 & 2.66 & 0 & 100 \\
\hline Any position which is comfortable & 2 & 2.66 & 75 & 0 \\
\hline No response & 21 & 28 & 0 & $\mathbf{1 0 0}$ \\
\hline Total & $\mathbf{7 5}$ & $\mathbf{1 0 0}$ & $\mathbf{7 5}$ & 0 \\
\hline
\end{tabular}

During counseling, the subjects were shown flashcards showing the positions in which the baby can be fed. It was emphasized that the baby can be fed in any position which is comfortable for both the mother and the baby. The pre test concept of participants to give bath, to cradle, or to put to sleep after the baby is fed is changed. $100 \%$ of the participants knew that the baby has to be burped after the counseling.

Table No 2: Showing perception of duration of one breast feed in the study group.

\begin{tabular}{|c|c|c|c|c|c|}
\hline \multirow{3}{*}{$\begin{array}{c}\text { Duration } \\
\text { Options }\end{array}$} & \multicolumn{4}{|c|}{ Opinion } & \multirow{3}{*}{$\begin{array}{c}\text { Statistical analysis } \\
\chi^{2} \text { test df } P \text { value }\end{array}$} \\
\hline & \multicolumn{2}{|c|}{ Pre test } & \multicolumn{2}{|c|}{ Post test } & \\
\hline & No & Percent & No & Percent & \\
\hline 5 minutes & 6 & 8 & 00 & 00 & \\
\hline 9 minutes & 8 & 10.66 & 68 & 90.6 & \\
\hline $1 / 2$ hour & 3 & 4 & 6 & 8 & \\
\hline 1 hour & 1 & 1.33 & 0 & 0 & \\
\hline No response & 57 & 76 & 1 & 1.33 & $88.161<0.001\left(\mathrm{HS}^{*}\right)$ \\
\hline Total & 75 & 100 & 75 & 100 & \\
\hline
\end{tabular}

*HS- Highly Significant 
As seen in the above table $76 \%$ participants in the pretest did not have any idea about the duration of breastfeeding hence did not respond. After counseling $90 \%$ of participants could recollect that the average duration of breastfeeding is 9 minutes. This change was analyzed to be statistically significant.

Table No.-3: Showing perception of interval between two breast feeds in the study group.

\begin{tabular}{|c|c|c|c|c|}
\hline \multirow{2}{*}{ Options } & \multicolumn{2}{|c|}{ Pre test } & \multicolumn{2}{c|}{ Post test } \\
\cline { 2 - 5 } & No & Percent & No & Percent \\
\hline 1 hour & 16 & 21.33 & 8 & 86.66 \\
\hline 3 hours & 10 & 13.33 & 05 & 00 \\
\hline 7 hours & 1 & 1.33 & 00 & 00 \\
\hline 9 hours & 1 & 1.33 & 2 & 2.66 \\
\hline No response & 47 & 62.66 & $\mathbf{1 5}$ & $\mathbf{1 0 0}$ \\
\hline Total & $\mathbf{7 5}$ & $\mathbf{1 0 0}$ & $\mathbf{7 5}$ \\
\hline
\end{tabular}

After counseling, $86.66 \%$ came to know that the interval should be 3 hours, while $10.66 \%$ still felt that the interval should be 1 hour.

Table No.-4: Showing opinion about the duration of exclusive breastfeeding and total duration of breastfeeding.

\begin{tabular}{|c|c|c|c|c|c|c|c|c|c|}
\hline \multirow{3}{*}{$\begin{array}{l}\text { Duration of } \\
\text { exclusive breast } \\
\text { feeding }\end{array}$} & \multicolumn{4}{|c|}{ Opinion } & \multirow{3}{*}{$\begin{array}{l}\text { Total duration } \\
\text { of } \\
\text { breastfeeding }\end{array}$} & \multicolumn{4}{|c|}{ Opinion } \\
\hline & \multicolumn{2}{|c|}{ Pretest } & \multicolumn{2}{|c|}{ Post test } & & \multicolumn{2}{|c|}{ Pre test } & \multicolumn{2}{|c|}{ Post test } \\
\hline & No & Percent & No & Percent & & No & Percent & No & Percent \\
\hline First 6 months & 40 & 53.33 & 74 & 98.66 & Up to 1 year & 12 & 16 & 2 & 2.66 \\
\hline First 2-3 months & 2 & 2.66 & 1 & 1.33 & $1-1 \frac{1}{2}$ years & 6 & 8 & 5 & 6.66 \\
\hline First 8 months & 3 & 4 & 00 & 00 & $11 / 2-2$ years & 16 & 21.33 & 63 & 84 \\
\hline Up to 1 year & 13 & 17.33 & 00 & 00 & $>2$ years & 11 & 14.66 & 4 & 5.33 \\
\hline No response & 17 & 22.66 & 00 & 00 & $\begin{array}{c}\text { Continued as } \\
\text { per need }\end{array}$ & 1 & 1.33 & 0 & 0 \\
\hline & & & & & No response & 29 & 38.66 & 1 & 1.33 \\
\hline Total & 75 & 100 & 75 & 100 & Total & 75 & 100 & 75 & 100 \\
\hline
\end{tabular}

It was observed that after counseling $98.66 \%$ of the participants felt that the baby should be exclusively breast fed for 6 months and $84 \%$ of the subjects felt that they should continue breast feeding for $1 \frac{1 / 2}{2} 2$ years.

Table No.-5: Showing awareness about the appropriate colour of the stool of exclusive breastfeeding baby

\begin{tabular}{|c|c|c|c|c|c|}
\hline \multirow[b]{2}{*}{ Options } & \multicolumn{2}{|c|}{ Pre test } & \multicolumn{2}{|c|}{ Post test } & \multirow{2}{*}{$\frac{\text { Statistical analysis }}{\chi^{2} \text { Test df } P \text { value }}$} \\
\hline & No & Percent & No & Percent & \\
\hline Green color & 1 & 1.33 & 0 & 0 & \\
\hline Straw colored & 2 & 2.66 & 0 & 0 & \\
\hline Golden yellow coloured & 7 & 9.33 & 75 & 100 & $\begin{array}{c}1241<0.001 \\
\left(\mathrm{HS}^{*}\right)\end{array}$ \\
\hline Brown coloured & 0 & 0 & 0 & 0 & \\
\hline No response & 65 & 86.66 & 0 & 0 & \\
\hline Total & 75 & 100 & 75 & 100 & \\
\hline
\end{tabular}

*HS- Highly significant

We observed that before counseling only $9.33 \%$ participants were aware of the color of stool of exclusively breast fed baby. Counseling led to a statistically significant change in the knowledge of the participants ( $\mathrm{P}$ value $<0.001)$ 
Table No.-6: Showing impression about the events that take place when the baby is satisfied.

\begin{tabular}{|c|c|c|c|c|}
\hline \multirow{2}{*}{ Opinions } & \multicolumn{2}{|c|}{ Pre test } & \multicolumn{2}{c|}{ Post test } \\
\cline { 2 - 5 } & No & Percent & No & 0 \\
\hline Baby will leave the nipple & 6 & 8 & 0 & 0 \\
\hline Baby will calm down and sleep & 22 & 29.33 & 0 & 0 \\
\hline Baby will pass motion or urine while feeding & 2 & 2.66 & 0 & 100 \\
\hline All of these & 1 & 1.33 & 75 & 0 \\
\hline No opinion & 44 & 58.66 & 0 & $\mathbf{1 0 0}$ \\
\hline Total & $\mathbf{7 5}$ & $\mathbf{1 0 0}$ & $\mathbf{7 5}$ & $\mathbf{1 5}$ \\
\hline
\end{tabular}

Before counseling $58.66 \%$ of the participants had no clue about the events that occur when the baby is satisfied. After counseling all the subjects (100\%) developed the correct impression about the events that take place once the baby is satisfied.

Table No.-7: Showing awareness about the breast problems occurring during breastfeeding.

\begin{tabular}{|c|c|c|c|c|}
\hline \multirow{2}{*}{ Opinions } & \multicolumn{2}{|c|}{ Pre test } & No & Percent \\
\cline { 2 - 5 } & No & Percent & 0 & 0 \\
\hline Cracked nipples & 0 & 0 & 0 & 0 \\
\hline Breast engorgement & 2 & 2.66 & 0 & 0 \\
\hline Inverted nipples & 1 & 1.33 & 0 & 100 \\
\hline Breast abscess & 3 & 4 & 75 & 0 \\
\hline All of these & 5 & 6 & 0 & $\mathbf{1 0 0}$ \\
\hline No opinion & 64 & 85.33 & $\mathbf{7 5}$ & $\mathbf{1 0 0}$ \\
\hline Total & $\mathbf{7 5}$ & $\mathbf{1 5}$ & \\
\hline
\end{tabular}

As seen in table no 7 counseling improved the knowledge about the breast problems that could happen to the mothers during breastfeeding.

Table No. 8: Showing impression about the management of breast engorgement

\begin{tabular}{|c|c|c|c|c|c|}
\hline \multirow{2}{*}{ Opinions } & \multicolumn{2}{|c|}{ Pre test } & \multicolumn{2}{c|}{ Post test } & Statistical analysis \\
\cline { 2 - 5 } & No & Percent & No & Percent & $\chi^{2}$ test df P value \\
\hline Stop feeding & 0 & 0 & 0 & 0 & \\
\hline Suppress lactation & 0 & 0 & 0 & 0 & \\
\hline Bxpress milk and continue feeding & 10 & 13.33 & 75 & 100 & $114.71<0.001\left(\mathrm{HS}^{*}\right)$ \\
\hline $\begin{array}{c}\text { Both to stop feeding or suppress } \\
\text { lactation }\end{array}$ & 2 & 2.66 & 0 & 0 & \\
\hline No response & 63 & 84 & 0 & 0 & \\
\hline Total & 75 & 100 & 75 & 100 & \\
\hline
\end{tabular}

* HS - Highly Significant

The pregnant women seem to be unaware of the fact that they could still continue to feed. After counseling, all the participants came to know that in the event of breast engorgement they should express milk and continue feeding. 


\section{Discussion}

In the present study it was found that the mean gestational age of the primigravida subjects was $37.9 \pm 1.47$ weeks.

$85.33 \%$ of the subjects were $20-25$ years old and $14.66 \%$ belonged to $26-30$ years age group. The average age of primigravida subjects in this current study was $23.15 \pm 2.22$ years suggesting similar cultural influences on the average age of primigravida $[10,11,12]$. There is a positive correlation regarding average age with Indian studies where the cultural factors would be similar $[11,12]$.

In the current study $82.66 \%$ of the subjects were Hindus and $17.33 \%$ were Buddhist which is representative of the proportional number of women attending the antenatal clinic in our tertiary care rural hospital which does not match with the study in which $71 \%$ Christians and $28.2 \%$ were Muslims which could be because of geographical distribution of religion [12]. However we feel that this demographic variable will not have any impact on the outcome of the study.

As the hospital is located in the outskirts of the city where nuclear families are not uncommon we found that more than half of the subjects belonged to joint family while $34.66 \%$ belonged to nuclear family which agrees with the other studies[10,11]. Probably with a larger sample size this finding may not hold true.

As increased proportion of girls are encouraged to study at least up to higher secondary school certificate examination which is a minimum qualification to seek jobs and courses in the university we found that most of the participants had obtained education up to higher secondary grade agreeing well with other studies $[11,12]$.

In the present study $86.66 \%$ of the participants were housewives, $10.66 \%$ were employed in the private sector.The observations about occupation could be because of the sociocultural and economic factors where even if the woman is educated she might not work as found in the other studies [10 ,12]. Many pregnant women towards the date of delivery may not attend their jobs as they need increased hours of rest.
Due to strengthening of the implementation of the BFHI activities over a decade and the health messages through the media participants agree that breast milk is the best food for the baby which is found to match with other studies $[9,10]$. This finding in the current study does not co relate with the study done by [8].

In the current study we observed that almost half of the participants $(50.66 \%)$ did not know what colostrum is and its function. However all of them felt that colostrum should be given to the baby. The fact that colostrum is necessary for all of the functions as mentioned in the options of the questionnaire needs to be strongly emphasized in future counseling guidelines as suggested in other studies [8,12].

We think that the wide spread health messages about breastfeeding via media in our community gives intense importance on the fact that 'the mother's milk is the best milk for the baby'. Hence, $98.66 \%$ of the participants in the current study feel that breastfed baby is a healthy baby which is contrary to the observations in the Nigerian sub urban women who felt that infant formula kept the body in good shape [12].

The current study also suggests that even the educated women may not have appropriate knowledge about the type, portions, composition of nutritious diet and that there are no dietary restrictions for lactating mothers. Therefore counseling must include dietary advice about portions of proteins, Iron, Calcium and calories $[8,10]$.

As women may be influenced by varied advice by the relatives or friends, counseling on early initiation of breastfeeding brings an enormous change in knowledge about the custom to feed the baby as soon as possible needs to be further emphasized. This finding is similar to other studies $[10,11]$.

Women have different beliefs about the position and technique of feeding the baby and may adopt positions related to individual comfort and convenience [12]. In addition to verbal counseling, use of flashcards as done in current study, visual media enhances learning and retains the learnt 
behavior in the receptive group of learners like pregnant women who are interested in the welfare of the baby. Baby can be fed in any position which is comfortable for both the mother and the baby was seen clearly in the posttest results [10].

The vague ideas about duration and interval between two feeds could be because of widespread belief that the baby would cry when hungry and should only be fed on demand basis and views of the influencing caretaker lady in the household as seen in the pretest of the current study.

Counseling brought a significant change $(\mathrm{P}$ value $<0.001$ ) about knowledge of duration an interval between feeds and the duration of exclusive breastfeeding which was also noted in the other studies $[9,10]$. The short duration of current study does not assure sustainability of exclusive breastfeeding for 6 months as per recommendations of BFHI. [2,11,12]

The participants in the current study had little or no knowledge about colour of stool of exclusively breastfed baby, events indicating baby's satisfaction, awareness about common breast problems and need to continue breastfeeding in the event of engorgement in the primigravida. Most of these common and day to day issues during breastfeeding can be known to mothers by active support of a female relative or a friend [7]. Hence, educational programs which are culturally and ethnically relevant should also be developed for a female relative or a friend who is likely to influence the mother's attitude and practices towards breastfeeding.

\section{Conclusion}

From the above study we can conclude that the existing knowledge about breastfeeding in primigravida is inadequate. There are gaps at household, community, and institutional levels. There is a priority to strengthen antenatal counseling on breastfeeding, in the domains which include importance of colostrum, nutrition, early initiation of breastfeeding after delivery, exclusive breast feeding, breast feeding positions, importance of burping, events indicating baby's satisfaction and common breast problems. Strategies should be designed to inform all pregnant women about the benefits of breastfeeding and reinforcing recommended breastfeeding practices in a given setting. If appropriate measures are undertaken to strengthen training in breastfeeding counseling and the number of trained professional/peer counselors at all levels is increased, exclusive breastfeeding might become a social norm, as evident in the post test results which showed that the subjects demonstrated good knowledge and a positive attitude towards breastfeeding after counseling.

Hence, this finding in the study can serve to develop the plan for the priority areas in the antenatal health education on breast feeding.

\section{Limitations of the study}

1) The duration of the study is 2 months.

2) Contact with the counselor is only once before the delivery at 36 weeks of gestation.

3) The post test is conducted in the immediate post partum period which is 4 days to 1 month after the pretest.

4) All the aspects related to breast feeding are not covered in the study.

5) Study cannot address sustainability of exclusive breast feeding up to 6 months.

\section{Funding: Nil, Conflict of interest: None Permission of IRB: Yes}

\section{References}

1. National guidelines on infant and young child feeding.Ministry of Human Resource Development Department of Women and Child Development (Food and Nutrition board). Government of India 2004 http://wcd.nic.in/ nationalguidelines.pdf

2. Carolina Global Breast feeding institute, Department of maternal and child health, Gillings school of global public health, University of north Carolina Global baby friendly hospital initiative monitoring data: update and discussion.

3. Kingston D, Heaman M, Fell D Chalmers B. Maternity Experiences Study group of Canadian Perinatal surveillance System, Public Health Agency of Canada. "Comparison of adolescent, young adult, and adult women's maternity experiences and practices". Peadiatrics 2012 May;129(5). 
4.Sanghvi T, Jimerson A, Hajeebhoy N, Zewale M, Nguyen GH. And young child feeding practices in different country settings. Food Nutr Bull. 2013 Sep;34(3 Suppl):S169-80.

5. Onayade AA, Abiona TC, Abayomi IO, Makanjuola RO. The first six month growth and illness of exclusively and non-exclusively breastfed infants in Nigeria. East Afr Med J. 2004 Mar;81(3):146-53.

6. Shankar Narayan, Nisha Natarajan, Dr. KS Bawa. "Maternal and neonatal factors adversely affecting breastfeeding in the perinatal period". Medical Journal Armed Forces India, 2005 Jul; 61 (3): 216-219.

7. Losch M, Dungy CI, Russell D, Dusdieker LB. Impact of attitudes on maternal decisions regarding infant feeding. J Pediatr. 1995 Apr;126(4):507-14.

8. Chaturvedi P, Banait N. Knowledge and attitude regarding breast-feeding, in mothers attending antenatal clinics. Indian J Pediatr. 2000 Apr;67 (4):259-62.
9. Su LL, Chong YS, Chan YH et al. "Antenatal education and postnatal support strategies for improvingrates of exclusive breast feeding: randomized controlled trial". BMJ 2007; Sep 22; 335 (7620):596.

10.Dhandapany G, Bethou A, Arunagirinathan A, Ananthakrishnan S. Antenatal counseling on breastfeeding -- is it adequate? A descriptive study from Pondicherry, India. Int Breastfeed J. 2008 Mar 4;3:5. doi: 10.1186/1746-4358-3-5.

11. Rajesh K Chudasama, Panna C Patel, and Abhay B Kavishwar. "Determinants of Exclusive Breastfeeding in South Gujarat Region of India”. Journal of Clinical Medicine Research. 2009 Jun; 1(2): 102-108. doi: 10.4021/jocmr 2009. 06.1242

12. Chidozie E Mbada, Adekemi E Olowookere, Joel O Faronbi, et al. "Knowledge, attitude and techniques of breastfeeding among Nigerian mothers from a semi-urban community". BMC Research Notes. 2013, 6:552. DOI: 10.1186/ 17560500-6-552.

\section{How to cite this article?}

Waikar A, Bhalerao A, Waikar M. Knowledge, attitude and practices of breast feeding in primigravida women in tertiary care hospital in central India. Int J Med Res Rev 2017;5(07):702-709.doi:10.17511/ijmrr. 2017.i07.08. 